\title{
KONSTRUKSI REALITAS PROGRAM ACARA MATA NAJWA TRANS7 (ANALISIS FRAMING ROBERT N. ENTMAN PADA ACARA MATA NAJWA EDISI UU OMNIBUS LAW CIPTA KERJA)
}

\author{
Construction Reality Program Mata Najwa Trans7 \\ (Analysis Framing Robert N. Entman At The Mata Najwa Edition Of The Omnibus Law \\ Copyright Work)
}

\author{
Megi Ardiansyah* \\ * Pascasarjana Universitas \\ Lampung, Kota Bandar \\ Lampung, Indonesia
}

email: megiariansyah97@gmail.com

\section{Kata Kunci:}

Talkshow

Framing

Kosntruksi Realitas

Keywords:

Talkshow

Framing

Reality Construction

\section{Accepted}

Juli 202I

Published

October 2021

\begin{abstract}
Abstrak
Saat ini banyak sekali muncul talkshow-talkshow di televisi. Konsep talkshow pun sangat beragam. Salah satunya konsep talkshow Matanajwa ini merupakan Talkshow berita yang mengangkat mengenai suatu peristiwa atau isu. Setiap edisinya pun mempunyai tema yang sangat beragam salah satunya "UU Omnibus Law Cipta Kerja" yang mengangkat sebuah berita atau peristiwa yang ramai diperbincangkan. Jurnal ini meneliti tentang bagaimana konstruksi realitas pada talkshow Matanajwa edisi "UjianReformasi" di Trans7. Penelitian ini mengggunakan paradigma konstruktivisme dengan pendekatan kualitatif dan metode analisis framing model Robert N. Entman. Dalam penelitian ini yang menjadi focus penelitian adalah video talkshow Matanajwa edisi "UU Omnibus Law Cipta Kerja" yang juga digunakan penelitian sebagai data. Hasil penelitian ini menunjukan sudut pandang bahwa program talkshow Matanajwa melihat peristiwa aksi demontrasi mahasiswa terhadap penolakan UU Omnibus Law Cipta Kerja ini sebagai bentuk perjuangan mahasiswa demi mewakilkan suara rakyat. Secara garis besar dari segment yang dianalisis, Hampir keseluruhan segment yang ditayangkan oleh Matanajwa cenderung menampilkan citra negatif DPR dan memandang tindakan atau sikap pihak pemerintah sebagai penyebab masalah baik melalui prolog narasi, pertanyaan yang diajukan dan tayangan yang ditampilkkan. Matanajwa yang kini tayang di Trans7, terlihat tunduk pada kepentingan modal atau pasar, dan dari sisi realitas Matanajwa membuat konstruksi realitas keberpihakan pada mahasiswa.
\end{abstract}




\section{PENDAHULUAN}

Komunikasi sebagai bentuk interaksi manusia dalam menyampaikan segala maksudnya, dari tahun ketahun mengalami kemajuan dari berbagai segi, perkembangan teknologi saat ini membuat setiap orang dapat menikmati produk media massa kapan saja dan dimana saja, baik itu anak-anak sampai orang dewasa. Agar kita lebih memahami definisinya dan ruang lingkup pembahasan.

Sebagaimana yang diketahui bahwa media-media di seluruh dunia akan menjadi sebuah agen penyebar pesan yang akan memberikan pengaruh serta mencerminkan sebuah kebudayaan di masyarakat, informasi - informasi ini akan dihadirkan bersamaan pada khalayak luas yang beragam. Hal tersebut akan membuat media menjadi bagian dari salah satu agen penyebar pesan yang kuat di masyarakat. Media massa menjadi otoritas tunggal yang menyeleksi, memproduksi pesan, dan menyampaikan pada khalayak.

Tujuan komunikasi untuk menyampaikan informasi kepada khalayak luas. Proses penyampaian pesan atau informasinya ditujukan kepada khalayak luas dengan menggunakan media massa sebagai alat sehingga pesan yang disampaikan dapat diterima secara bersamaan dengan mengharapkan umpan balik.Komunikasi massa yang di tujukan kepada hal layak.

Pada kehidupan zaman global dan modern sekarang, televisi yang lebih unggul dari media lainnya dengan bentuk video-visualnya sangat dibutuhkan keberadaannya bagi setiap lapisan masyarakat, karena kedudukan televisi penting sebagai alat penyampaian berbagai informasi seperti bisnis, pendidikan, hingga hiburan, lebih tepatnya televisi juga digunakan sebagai alat propaganda politik. (Ardianto dkk, 2007:I34).

Talkshow Matanajwa juga memiliki citra yang kuat sebagai salah satu program talkshow yang mengangkat isu atau fenomena penting yang sedang hangat di perbincangkan seperti isu politik, toleransi, dan isu sosial masyarakat sehingga menjadi referensi saat ada isu tertentu. Salah satu konsep talkshow Matanajwa ini merupakan talkshow berita. Setiap episodenya pun mempunyai tema yang sangat beragam salah satunya “UU Omnibus Law Cipta Kerja” merupakan talkshow yang membahas sebuah berita yang ramai diperbincangkan.

Karena banyaknya media yang membahas mengenai peristiwa tersebut, maka banyak pula media yang tentunya memilki konstruksi yang berbeda dalam membingkai peristiwa tersebut. Berita aksi mahasiswa dalam menolak UU Omnibus Law Cipta Kerja ini menjadi topik utama (headline) di televisi nasional maupun swasta, salah satunya Trans7.

Konstruksi yang dibuat itu dilengkapi dengan sumber kebenaran tertentu, bahwa apa yang dikatakan benar adanya, punya dasar yang kuat. Pemberitaan tentang aksi mahasiswa dalam menolak UU Omnibus Law Cipta Kerja mengangkat berbagai polemik, yaitu memunculkan pro dan kontra terhadap pemerintah. Dalam pembentukan opini publik media berperan sangat penting karena media mengkonstruksi isu atau fenomena tersebut. Konstruksi Realitas Program Acara di Trans7.

Penelitian ini mengarahkan kepada suatu konsep pendekatan bertujuan untuk mengetahui cara pandang yang dilakukan oleh wartawan dalam memilah isu dalam isi berita dengan persepektif untuk menentukan fakta yang akan dinaikkan serta bagian mana yang akan diberikan penekanan dalam menentukan kemana berita tersebut akan mengarah. Sebuah cara bagaimana peristiwa disajikan oleh media. Penyajian berita akan dilakukan dengan memberikan penekanan pada bagian tertentu, menonjolkan aspek tertentu serta memaksimalkan cara berita dari sebuah fakta.

Media menghubungkan dan menonjolkan peristiwa sehingga makna dari periistiwa tersebut lebih mudah diingat oleh khalayak. Framing merupakan 
metode penyajiian realitas dimana kebenaran tentang suatu kejadian tidak diingkari secara total, melainkan diibelokkan secara halus, dengan menojolkan aspekaspek tertentu, dengan menggunakan istilah-istilah yang punya konotasi tertentu dengan bantuan foto, karikatur dan lainnya (Kriyantono, 2006:253).

Sejatinya setiap individu memiliki ideologi dan kepentingan yang berbeda. Individu tersebut berusaha untuk memberikan penonjolan konsep, dalam tujuannya memberikan makna terhadap objek wacana dari keterlibatan individu dalam sebuah pembahasan yang dipengaruhi oleh status, ilmu pengetahuan, serta pengalaman social masing - masing pihak. Bagian inilah pada media massa yang kemudian menjadi sebuah arena perang secara symboli antarin individu - individu yang memiliki kepentingan terhadap sebuah wacana. Perdebatan yang terjadi tentunya secara simbolik, sehingga lumrah ditemukannya bermacam perangkat bahasa atau wacana yang melampirkan tendensi untuk memberikan legitimasi terhadap diri sendiri dan mendelegitimasi pihak lawan.

Dari hal tersebut terlihat bahwa framing tidak hanya berkaitan dengan satu pihak (wartawan) semata, akan tetapi juga berhubungan dengan hal lain seperti proses pembuatan berita, perangkat kerja, serta operasional media. Tahapan - tahapan dalam menganalisis permasalahan. Secara garis besar tinjauan meliputi teori komunikasi massa, melalui media massa modern, yang meliputi surat kabar yang mempunyai sirkulasi yang luas, siaran radio dan televisi yang ditujukan kepada umum, dan film.

Komunikasi massa mendefiniskan Secara garis besar pemahaman konsep tentang komunikasi massa dilakukan dengan menggunakan media massa seperti televisi dan radio yang ditujukan kepada khalayak yang luas,proses dalam sebuah sistem sehingga menimbulkan efek dan diuji dalam sebuah teori yang menjadi fenomena terkait dengan proses komunikasi secara luas. Artinya komunikator dalam komunikasi massa dalam menyebarkan pesan-pesannya mencoba berbagi pengertian dengan jutaan orang yang tidak saling kenal atau mengetahui satu sama lain.

Jenis pekerjaan yang berbeda satu dengan lainnya, usia adat, kebiasaan dan kebudayaan yang berbeda. Sedangkan anonim adalah bahwa khalayak yang ada terdiri dari orang-orang yang masing-masing tidak saling mengenal dengan yang lainnya. Dalam perkembangannya, memiliki beberapa fungsi dalam prosesnya menyebarkan sebuah informasi. Fungsi Informasi memberikan bahwa media massa adalah penyebar informasi bagi pembaca, pendengar atau pemirsa. Berbagai informasi dibutuhkan oleh khalayak media massa yang bersangkutan sesuai dengan kepentingannya. Khalayak sebagai makhluk sosial akan selalu merasa haus akan informasi yang terjadi dan fungsi Media massa merupakan sarana pendidikan bagi khalayak. Karena media massa banyak menyajikan halhal yang sifatnya mendidik.

Salah satu cara mendidik yang dilakukan media massa adalah melalui pengajaran nilai, etika, serta aturan-aturan yang berlaku kepada pemirsa atau pembaca. Secara implisit terdapat pada tajuk/editorial, features, iklan dan artikel. Khalayak dapat terpengaruh oleh iklan-iklan yang ditayangkan televisi ataupun surat kabar. Tiada lain tujuannya adalah untuk megurangi ketegangan pikiran khalayak, karena dengan membaca beritaberita ringan atau melihat tayangan hiburan di televisi dapat membuat pikiran khalayak segar kembali (Ardianto, Komala, Karlinah, 2007: 17-19).

Media merupakan sebuah sarana yang banyak digunakan untuk menyampaikan sebuah pesan dari individu satu kepada individu lainnya, antar manusia, dengan media yang paling dominan adalah panca indera seperti mata dan telinga. Pesan yang diterima oleh panca indera tersebut akan diproses dalam pikiran manusia sebagai komando untuk mengontrol dan menentukan sikap terhadap sesuatu, sebelum pada akhirnya akan dinyatakan pada tindakan.

Konstruksi pada media melalui sebuah pemberitaan yang muncul di khayalak ramai bersumber 
pada cara pandang dari penentuan berita, dimana bahasa menjadi suatu unsur paling utama untuk memaparkan realitas, sehingga nilai-nilai yang diterapkan mudah untuk dipahami dan dimaknakan. Framing hadir sebagai proses pemaknaan dan cara dari bagaimana suatu media tertentu untuk menyajikan berita, baik ditilik dari penekanan bagian tertentu dan bagaimana media tersebut bercerita.

Penelitian yang dilakukan menggunakan teknik analisis framing sebagai cara untuk melihat bagaimana peristiwa disajikan oleh media. Penyajian yang dimaksud merupakan penonjolan dari aspek tertentu, memberikan maksimalisasi cara menyajikan berita tertentu dari sebuah fakta peristiwa. Media menjadi penghubung dan penonjol sebuah wacana sehingga pengertian dari wacana tersebut diingat oleh khalayak ramai. Seperti yang dikatakan oleh Frank D. Durham, framing menjadikan dunia lebih dimaknai dan dimengerti. Dalam buku Mulyana, pandangan subjektif menyebut realitas social sebagai sebuah kondisi yang melebur dan dinamis melalui interaksi manusia terhadap kehidupannya sehari-hari. (Mulyana,2006: 34).

\section{METODOLOGI}

Penelitan ini menggunakan pendekatan kualitatif dengan prespektif paradigma konstruktivis. Eriyanto (2002:32), pendekatan konstruksionis yang ada pada analisis framing akan mencakup aspek etika, moral, dan nilai-nilai tertentu dari pemberitaan yang ada. Wartawan bukanlah robot yang meliput apa adanya berdasarkan apa yang dia lihat namun berdasarkan etika dan moral yang dalam banyak hal berarti keberpihakan pada satu kelompok atau nilai tertentu yang umumnya dilandasi oleh keyakinan tertentu. Hal ini merupakan bagian yang integral dan tidak terpisahkan dalam membentuk dan mengkonstruksi realitas. Wartawan dalam hal ini bukan hanya sebagai pelapor, karena disadari atau tidak ia menjadi partisipan dari keragaman penafsiran dan subjetivitas publik. Oleh karena fungsinya tersebut, maka wartawan menulis berita bukan hanya sebagai penjelas, tetapi juga mengkonstruksi peristiwa melalui dirinya sendiri dengan realitas yang diamatinya. Analisis framing adalah salah satu metode analisis teks yang berada dalam kategori penelitian konstruksionis. Paradigma ini memandang realitas kehidupan sosial bukanlah realitas yang natural, tetapi hasil dari konstruksi. Jadi setiap media massa dapat berbedabeda dalammengkonstruksikan isu yang terjadi.

Fokus penelitian yaitu talkshow Matanajwa edisi “UU Omnibus Law Cipta Kerja” di Trans7 berdurasi kurang lebih 90 menit yang membahas mengenai aksi mahasiswa dalam tolak UU Omnibus Law Cipta Kerja.

Dalam penelitian ini adalah analisis framing oleh Robert N. Entman, seperti apa konstruksi realitas tayangan program Matanajwa di mediaTrans7 seperti apa wartawan dalam melihat isu terhadap aksi mahasiswa dalam menolak UU Omnibus Law Cipta Kerja. Saat ini telah banyak metode yang berpijak dari pendekatan analisis isi kualitatif seperti analisis framing, analisis wacana, semiotika, analisis retorika, dan ideological criticism (Kriyantono, 2006:250).

Adapun penelitian ini menggunakan banyak sumber data yang dikelompokkan atas dua bagian yaitu: Data primer diperoleh langsung dari objek penelitian yaitu talkshow Matanajwa edisi "UU Omnibus Law Cipta Kerja” dengan mengunduh tayangan Matanajwa dari internet. Dan data sekunder yaitu data pelengkap yang berkaitan dengan penelitian berupa sumber dari referensi, buku dan jurnal penelitian maupun internet, Peneliti juga menggunakan teknik dokumentasi publik, yaitu televisi dan internet. Dari video tayangan Matanajwa tersebut, peneliti menggunakan analisis model framing Robert N. Entman dengan melakukan teknik analisis data melalui tahapan.

Reduksi data merupakan kegiatan memilih, menggolongkan, mengarahkan, membuang yang tidak perlu, sesuai dengan fokus penelitian, 
Display data yaitu tahap menyajikan data dalam bentuk yang disesuaikan atau diklarifikasi untuk mempermudah peneliti dalam menguasai data dan menganalisis data sehingga mudah dipahami,

Verifikasi data yaitu data yang berguna untuk menguji relevansi antara display data dengan kerangka analisis serta tujuan penelitian yang telah ditetapkan. Data disajikan berupa hasil kesimpulan dari keseluruhan data yang diteliti.

\section{HASIL DAN PEMBAHASAN}

Dalam penelitian ini sebanyak segment pada tayangan talkshow Matanajwa "UU Omnibus Law Cipta Kerja” pada hari Rabu I4 Oktober 2020 20:00 WIB telah dianalisis dengan maksud untuk melihat pengemasan atau pembingkaian pada tayangan tersebut terkait dengan peristiwa aksi demosnstrasi yang dilakukan mahasiswa. Setelah dilakukan analisis dengan pembahasan, peristiwa aksi mahasiswa dalam menolak UU Omnibus Law Cipta Kerja, penulis melihat adanya keberpihakan media Trans7 dalam menampilkan isu atau fakta. Dalam 7 segment pada talkshow Matanajwa edisi "UU Omnibus Law Cipta Kerja”. Secara garis besar dari segment yang dianalisis, Hampir keseluruhan segment yang ditayangkan oleh Matanajwa cenderung menampilkan citra negatif DPR dan memandang tindakan atau sikap pihak pemerintah sebagai penyebab masalah baik melalui prolog narasi, pertanyaan yangdiajukan dan tayangan yang ditampilkkan.

Matanajwa memperlihatkan ke publik mengenai sikap pemerintah dan aparat yang menampilkan citra buruk di mata masyarakat. Sedangkan mengenai mahasiswa Matanajwa memperlihatkan ke publik bahwa mahasiswa yang berjuang mewakilkan suara rakyat kepemerintah mengenai UU Omnibus Law Cipta Kerja pemasyarakatan yang bermasalah malah menjadi korban kericuhan dan difitnah oleh DPR.
Matanajwa mengkonstruksi citra buruk DPR dan anggap DPR sebagai penyebab masalah.

Matanajwa mendifinisikan peristiwa demonstrasi ini sebagai bentuk perjuangan mahasiswa untuk rakyat, dengan menampilkan alur jalannya demonstrasi yang diawali dengan damai hingga kemudian terjadi kericuhan yang perlihatkan mahasiswa menerobos pagar DPR dan bentrok antara mahasiswa dan aparat. Berkaitan dengan fungsi kontrol sosial membuktikan bahwa Matanajwa independent, walaupun pada tayangan Matanajwa memperlihatkan kekerasan yang dilakukan aparat.

Melalui penyampaian prolog narasi yang disampaikan Najwa Shihab dipenghujung acara, sangat jelas bahwa dengan penggunaan kalimat "UndangUndang disusun diam-diam Matanajwa mengajak publik untuk membenarkan aksi mahasiswa ini karena pemerintah yang tidak mendengar dan pedulikan rakyat. Matanajwa mengkonstruksi tayangan tersebut sebagai aksi perjuangan mahasiswa untuk rakyat menyuarakan hal yang benar sehingga Matanajwa mengajak publik membela dan berada di pihak mahasiswa.

Ditinjau dari ekonomi media, dapat di katakan Matanajwa yang kini tayang di Trans7 dengan kepemilikan media yang bukan orang politik, terlihat tunduk pada kepentingan modal atau pasar, dan dari sisi realitas Matanajwa membuat konstruksi realitas keberpihakan pada mahasiswa melalui pertanyaan dan tanggapan yang diajukan ke narasumber terlihat jelas lebih menonjolkan citra negatif pemerintah.

Sebuah talkshow mengangkat mengenai suatu peritiwa sebuah tayangan, aksi mahasiswa matanajwa menampilkan aparat yang tembaki atau siram mahasiswa dengan air sehingga menjadi penyebab kericuhan. Lewat bahasa prolog narasi yang dipakai, Najwa Shihab menyebutkan bahwa aksi mahasiswa ini adalah bentuk protes yang mewakili suara rakyat, ntuk menolak sebab pandangan konstruksionis, proses pemaknaan, ideology dari wartawan atau media. 
Dengan menayangkan alur demonstrasi yang diawali dengan damai kemudian terjadi kericuhan yang perlihatkan mahasiswa menerobos pagar DPR dan aparat yang lakukan kekerasan pada mahasiswa, hal ini memperkuat pernyataan yang memandang wartawan sebagai agen konstruksi, wartawan bukan hanya melaporkan peristiwa tapi terlibat dalam pendefinisian peristiwa.

\section{KESIMPULAN}

Berdasarkan hasil penelitian dan pembahasan, maka peneliti menyimpulkan beberapa hal sebagai berikut:Bahwa talkshow Matanajwa mengkonstruksi peristiwa aksi demontrasi mahasiswa terhadap penolakan "UU Omnibus Law Cipta Kerja” ini sebagai bentuk perjuangan mahasiswa demi rakyat, dan Matanajwa telah menunjukan keberpihkannya ke mahasiswa melalui pemakaian kata pada prolog narasi Najwa, pertanyaan dan dalam menampilkan tayangan alur aksi demonstrasi tersebut, dengan tujuan mengajak publik untuk mendukung dan berada dipihak mahasiswa.

Pemilihan narasumber, pertanyaan, dan tayangan alur demonstrasi pada talkshow Matanajwa bukanlah realitas yang nyata melainkan sebuah konstruksi dari sebuah media dengan tujuan untuk membela mahasiswa.

Matanajwa yang kini tayang di Trans7 terlihat tunduk pada kepentingan modal atau pasar, yang lebih mengedepankan rating dengan menampilkan apa yang ingin dilihat oleh pemirsa.

\section{REFERENSI}

Ardianto, Karlina, S. 2007. Komunikasi Massa. Bandung; Rekatama Media.

Burhan. 2015. Data Penelitian Kualitatif. Jakarta: Rajawali Pers.

Onong Uchnaja. 1993. Ilmu, Teori \& Filsafat; Citra

Aditya Bakti.
2002. Dinamika Komunikasi (Edisi

IV). Remaja Rosdakarya.

Eriyanto. 2002. (Konsruksi dan Politik Media). LKiiS.

Ikbar, Yanuar. 20I2. Metode Penelitian Sosial Kualitatif. Bandung: PT Rapika Aditama.

Rachmat. 2006. Riset Komunikasi. Jakarta: Media Group.

Moeleong. 2007. penelitian kualitatif (Cet. V). Remaja Rosdakarya.

Nurhadi, Zikri Fachrul. 20I5. Teori Komunikasi Dalam Penelitian Kualitatif. Ghalia Indonesia.

Ruslan, Rosady. 2008. Metode Penelitian Public Relation dan Komunikasi. Jakarta: PT RajaGrafindo Persada.

Tamburaka, Apriadi. 2012. Agenda Setting Media Massa. Jakarta; Rajawali Pers

Sumber lain:

Nastiti, R. 2018. Konstruksi Diskriminasi Perempuan

Dalam Pemberitaan Criminal Kompas.Com

(Analisis Framing Robert Etmant).

http://repositori.uinalauddin.ac.id// 265 I///KONSTRU

KSI\%20DISKRIMINASI\%20PEREMPUAN\%2

ODALAM\%20PEMBERITAAN\%20KRIMINAL\%20

DI\%20KOMPAS.pdf(3 Oktober 2019).

Faisal, F. 2017. (PROGRAMBREAKINGNEWS)

http://repository.UINalauddin.ac.id/I 2720/I/FAISALKo

nstruksi\%20berita\%20aksi\%202I2.pdf (3 Oktober 2019).

Rizal, M. 2013. Analisis Program Mata Najwa Episode Sengketa Iman DiMetroTV. (3 Oktober 2019).

“Analisis Frame Pemberitaan Di Media Online (Studi Kasus Pada Pemberitaan Penyerangan Novel Baswedan Dengan Air Keras Di Media Detik.Com)”, SKRIPSI, FISIP UNBARA, Baturaja, 2018.

https://id.wikipedia.org/wiki/Najwa_Shihab 